\title{
Correction to: Medicinal plants used by women in Mecca: urban, Muslim and gendered knowledge
}

\author{
Afnan Alqethami ${ }^{1}{ }^{2 *}$, Julie A. Hawkins ${ }^{1}$ and Irene Teixidor-Toneu ${ }^{1}$
}

\section{Correction}

In the original publication [1] Arabic names in Table 2 were transcribed from left to right. The corrected version of Table 2 can be found as Additional file 1 in this Erratum.

\section{Additional file}

Additional file 1: Comprehensive inventory of the plants listed by women in Mecca including the scientific name and family, whether the plant is found in the Flora of Saudi Arabia and whether it is used as a food or spice, vernacular name(s), part(s) used, therapeutic use categories, preparation, administration, toxicity and side effects, frequency of citation, and Smith's S. For presence or absence in the Flora of Saudi Arabia, $Y=y e s$, $\mathrm{N}=\mathrm{no}$; and for food and/or spice use, $\mathrm{F}=$ food and $\mathrm{S}=$ spice. Plants not documented in the selected literature are marked with *. (DOCX 53 kb)

Published online: 15 December 2017

\section{Reference}

1. Medicinal plants used by women in Mecca: urban, Muslim and gendered knowledge. J Ethnobiol Ethnomed. 2017;13:62. https://doi.org/10.1186/ s13002-017-0193-4.

\footnotetext{
* Correspondence: af14102009@hotmail.com

${ }^{1}$ Section of Ecology and Evolutionary Biology (EEB), Harborne Building,

School of Biological Sciences, University of Reading, Whiteknights, Reading RG6 6AS, UK

${ }^{2}$ Department of Biology, Faculty of Applied Science, Umm Al-Qura University, PO Box 715, Mecca 21955, Saudi Arabia
} 